\title{
Understanding Retailers' Acceptance of Virtual Stores
}

\author{
Irene Y.L. Chen* \\ Department of Accounting, National Changhua University of \\ Education, No.2, Shi-Da Road, Changhua City, 500 Taiwan, R.O.C. \\ E-mail: irene@cc.ncue.edu.tw \\ *Corresponding author
}

\begin{abstract}
The acceptance of e-commerce among consumers has stimulated the rise of virtual stores. Increasing traditional retailers or people who do not have sufficient capital for maintaining a brick-and-mortar store have considered using virtual stores to reach global market. In the e-commerce literature, there has been rich research evidence concerning consumers' acceptance of virtual stores. However, rigorous academic research on retailers' acceptance of virtual stores is relatively scarce today. This study draws upon the theory of planned behavior and information richness theory to propose an integrated theoretical model. A field survey is used to collect data from e-tailers. The data are analyzed to examine the six relationships posited in the research model. Findings of this study provide a further research avenue for e-commerce, and implications for those who are managing or considering using virtual stores.
\end{abstract}

Keywords: E-Commerce, E-Learning, virtual store.

Biographical notes: Irene Y.L. Chen is an assistant professor of Department of Accounting at National Changhua University of Education, Changhua, Taiwan. She received her $\mathrm{Ph} . \mathrm{D}$. degree in MIS from National Kaohsiung First University of Science and Technology. Her research interests include Webbased learning behavior, e-commerce and knowledge management. Her research findings have been published in Journal of Information Science, Computers \& Education, Educational Technology \& Society, International Journal of Human-Computer Studies, and Expert Systems with Applications.

\section{Introduction}

The Internet has become an important channel for companies to offer direct sales to their customers. Its capacity to access, organize and communicate information in a more efficient way enables firms to conduct business over the Internet. This type of business is referred to as e-business. With its dynamic, rapidly growing, and highly competitive characteristics, e-commerce promises new avenues for the creation of wealth (Amit \& Zott, 2001). Thus, e-commerce has now emerged as possibly the most representative distribution channel in a wide range of industry such as airline, commodity retailing, etc. One of the most visible business uses of the Internet is consumer retailing.

Chen and Tan (2004) pointed out that the new electronic medium has created opportunities for virtually all companies ranging from small start-ups to Fortune 100 companies. Retailers all over the world are establishing virtual stores, which exist in the cyberspace and offer merchandise and services through an electronic channel to their customers with a fraction of the overhead required in a bricks-and-mortar store (Chen \& 
Tan, 2004; Hoffman et al., 1996; Yesil, 1997). Given the lower setup costs, lower cost per customer contact, and lower maintenance cost of virtual stores, individuals can now easily own a virtual store (i.e., to become an e-tailer). Virtual stores often claim to provide greater convenience and product selections to consumers; nevertheless, price will still remain a major factor in consumer store choice. The right kinds of products offered by a virtual store can create cost advantages and attract customers (Chen \& Tan, 2004). Although the development of e-commerce offers great opportunities for both manufacturers and retailers (Crespo \& Bosque, 2008b), online sales volumes remain relatively low compared to traditional retailing (Shang et al., 2005).

The theory of planned behavior (TPB) is among the most influential theories in explaining and predicting a system use. It suggests that attitude is an important variable determining people's intention of performing a behavior and the occurrence of actual behavior. Attitude is also extensively discussed in the technology acceptance model (TAM) literature. The findings by TAM literature also corroborate the importance of attitude in determining the intention to perform a behavior. Some TAM-based studies have suggested that perceived usefulness influences attitude towards performing certain behavior. Other TAM-based studies found that information richness and product offerings, two important variables from Information Richness Theory (IRT) (Daft \& Lengel, 1986), significantly influence perceived usefulness in the e-commerce context (Chen \& Tan, 2004).

Recent rapid development of advanced information technology brings high expectations of its potential to improvement and innovations in learning (Chen et al., 2010, p.2). E-learning refers to learning that takes place anytime someone uses electronic means for gathering information that is acquired without another live person present (Zhang \& Nunamaker, 2003). It is a way e-tailers can gain knowledge. International retail companies, and fashion retailers in particular, are increasingly moving into international markets through the franchise mode of operation; supporting franchisees is a fundamental aspect of the international retail franchise process and is crucial to its success (Doherty, 2007). A key advantage in purchasing a franchise is training and the acquisition of technical expertise (Price, 1993). Franchise systems want their franchisees to understand and use the key management tools (Sayler, 2003). Prior studies have investigated the impact of training on employee's productivity. For example, evidence from McDonald's suggests that low levels of training give rise to high levels of staff turnover and that the provision of good training has a positive effect on staff retention (Thomas et al., 2000; Choo, 2007). However, little has been done to examine the effect of a training system on e-tailers' acceptance of virtual stores.

In the literature of e-commerce, numerous studies have investigated the factors influencing consumers' adoption of online shopping. However, rigorous academic research on retailers' acceptance of virtual stores is relatively scarce today. To fill this gap, this study will extensively review extant literature and analyze the factors that determine retailers' intention to use virtual stores to reach the global market. The present research model incorporates training system quality, information richness, product offerings and perceived usefulness into the theory of planned behavior. 


\section{Theoretical Background and Research Model}

Based on a literature review of the acceptance of e-commerce or intention to use a virtual community, this study draws upon TPB and prior research findings and proposes an integrated research model to validate previous research findings and better explain retailers' usage behavior of virtual stores. The proposed research model is depicted in Figure 1.

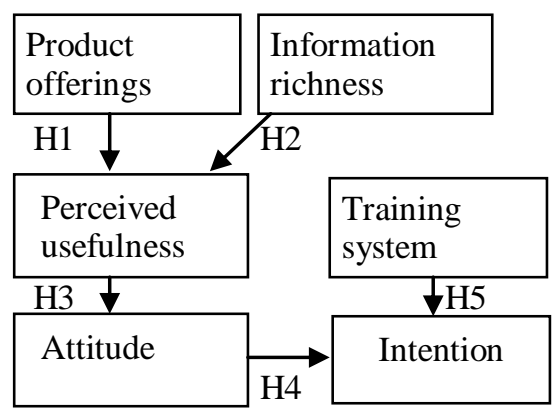

Figure 1. Research model

\subsection{Product offerings}

Consumers who choose to shop online instead of purchasing merchandise from brickand-mortar stores may expect virtual stores to offer a wider product variety than traditional retailers. Product variety is often an influential factor in retail store patronage (Woodside \& Trappey, 1992). A virtual store is an alternative to run business for those who do not have sufficient capital to establish brick-and-mortar stores, or for traditional retailers to reach online consumer market. However, they must first understand the commodity preference of those who search products from the Internet and place orders on Web. Specifically, for those who consider setting up a virtual store by signing a franchise agreement with a product brokerage company which provides personalized websites and holding and delivering merchandise to end customers, the combination of breadth of product selection, pricing strategies and product retail channel fit will be first evaluated before they make decision, because these factors will shape their consumers' product perception (Chen \& Tan, 2004). The following relationship is thus expected:

H1: The product offerings positively affect a retailer's perceived usefulness of a virtual store.

\subsection{Information richness}

Consumers use virtual stores for searching product information. According to the IRT (Daft \& Lengel, 1986), information richness is defined as 'the ability of information to change understanding within a time interval'. IRT also predicts that information richness is a major determinant of user media choices. Virtual stores are often described as 'super sales associates' for their direct and uninterrupted interactions with customers and abundant product information (Alba et al., 1997). Shopping is a voluntary behavior and different from the use of software packages and e-mail, it would be important for e-tailers to try to keep consumers on-line as long as possible (Shang et al., 2005). Hence, 
information richness of the personalized website provided by the franchisor plays a crucial role in shaping a retailer's decision to use a virtual store. Chen and Tan (2004) suggested that information richness is the antecedent of perceived usefulness. The following relationship is thus expected:

$\mathrm{H} 2$ : The information richness positively affects a retailer's perceived usefulness of a virtual store.

\subsection{Perceived usefulness}

On the basis of the technology acceptance model, prior research has derived mixed findings from field survey data about the influences of perceived usefulness and perceived ease of use on attitude toward e-commerce. Although Crespo and Bosque (2008a) reviewed extant literature and suggested that a few studies had shown empirical evidence which supports the significant influence of perceived usefulness on attitudes. In the context of e-commerce, their study (Crespo \& Bosque, 2008a) found that perceived usefulness had a significant impact on attitude. Shih (2004) also applied TAM to predict user acceptance of e-shopping on the Web; the result showed that perceived usefulness significantly affects individual attitudes toward e-shopping.

Perceived usefulness in this study refers to the extent to which retailers perceive that using virtual stores help to gain knowledge from the franchisor. Childers et al. (2001) found that perceived usefulness has positive impact on attitude toward the interactive media use. Moon and Kim (2001)'s study showed that perceived usefulness was positively related to attitude towards using the Web. Igbaria et al. (1995) found that perceived usefulness is the major reason for using computer technology. Hsu and $\mathrm{Lu}$ (2004) found that perceived usefulness significantly affects attitude toward playing an online game but do not significantly impact intention to play an online game. The following relationship is thus expected:

H3: Perceived usefulness positively affects a retailer's attitude towards using a virtual store.

\subsection{Attitude and Intention}

Attitude towards behavior refers to a global predisposition, for or against, developing such behavior; the individuals' attitudes have been included as determinants of intention or behavior in the models of consumer behavior (Crespo \& Bosque, 2008b). In the literature of e-commerce, the findings of many studies have suggested the influence of attitudes on the intention to use Internet as a purchase system or selling channel. Shih (2004) applied TAM to predict user acceptance of e-shopping on the Web, showing that attitudes toward e-shopping were strongly and positively correlated with user acceptance. Crespo and Bosque (2008b) found that general attitude to the system is the main factor determining the future intention to purchase online.

Retailers who consider using virtual stores as a selling channel need to judge whether consumers will buy the products provided by the product brokerage company on the Web, or these products can instead be easily found in chain stores such as the 7elevens. If there is a great potential to reach online consumer market by using a virtual store, an individual or a traditional retailer will hold positive attitude about using virtual 
stores as a selling channel; such attitude will play an important role in the formation of his/her intention to use a virtual store. The following relationship is thus expected:

H4: A retailer's attitude positively affects the intention to use a virtual store.

\subsection{Training system and Intention}

DeLone and McLean's (D\&M) (2004) IS success model has been widely used as a theoretical guideline in measuring e-commerce success. DeLone and McLean (2004) found that information quality, system quality and service quality of an e-commerce system jointly significantly influence users' intention to use the e-commerce system. Hence, this study posits that the overall quality in terms of information quality, system quality and service quality of the website of a virtual store has a positive impact on a retailer's intention to use a virtual store.

H5: The quality of a training system positively affects a retailer's intention to use a virtual store.

\section{Research Methodology}

\subsection{Structure of the survey and measurement scales}

In order to test the hypotheses, research aimed at e-tailers was developed. Scales that measure the constructs were generated from previous research and modified to fit the context of virtual store and the role of retailer when necessary. New items were developed through a thorough literature review on the topics. The items were written in the form of statements with which the respondent is to agree or disagree on a 5-point Likert scale.

Product offerings were measured by the items adapted from Chen and Tan (2004) and Jarvenpaa and Todd (1997). Information richness was measured by items adapted from Daft and Lengel (1986) and Chen and Tan (2004). Scales for perceived usefulness were adapted from existing studies on e-commerce (Shang et al., 2005; Shih, 2004; Crespo \& Bosque, 2008a). Measures for attitude were adapted from Kim et al. (2008a, 2008b), Chen and Tan (2004) and Crespo and Bosque (2008b). Intention was measured by Crespo and Bosque (2008a), Kim et al. (2008a) and Yu et al. (2005).

\subsection{Data collection}

Three MBA students and three PhD students with working or research experience within the framework of Internet users' behavior collaborated in the final survey definition. Thus, all the necessary changes were made according to the experts' comments starting from an initial draft survey. Also, a preliminary survey was conducted with another five graduate students majoring in information management in order to check adequate understanding of all questions. 
The research subjects include e-tailers who have franchise agreement with an Internet marketing company. This study asked the help from e-tailers to complete the survey. Small gifts were sent to the participants who completed the survey.

\section{Data Analysis}

\section{Measurement Model}

Reliability was examined using the Cronbach's alpha values. As listed in Table 1, all of these values were greater than 0.88 , well above the recommended threshold value of 0.6 . Convergent validity was evaluated for the measurement scales using two criteria suggested by Fornell and Larcker (1981): (1) all indicator factor loadings should be significant and exceed 0.70 , and (2) average variance extracted (AVE) by each construct should exceed the variance due to a measurement error for that construct (i.e., should exceed 0.50). As summarized in Table 1, AVEs ranged from 0.82 to 0.92 , greater than variance due to a measurement error. All items exhibited loadings higher than 0.7 on their respective constructs. These figures signify desirable convergent validity of the measurement.

Discriminant validity was evaluated through comparison of the AVE of construct pairs to the squared correlation between construct pairs. Fornell and Larcker (1981) recommended a test of discriminant validity, where the AVE should exceed the squared correction between that and any other construct. All of the items in Table 1 exhibited AVE greater than 0.82, which is the highest squared correlation between construct pairs. The overall results provide support for acceptable discriminant validity of constructs.

Table 1: Composite reliability and discriminant validity

\begin{tabular}{|c|c|c|c|c|c|c|c|}
\hline Construct & CR & 1 & 2 & 3 & 4 & 5 & 6 \\
\hline 1. Product offerings & .90 & .92 & & & & & \\
\hline 2. Information richness & .89 & .45 & .89 & & & & \\
\hline 3. $\quad$ Perceived usefulness & .90 & .41 & .55 & .89 & & & \\
\hline 4. Attitude & .90 & .54 & .55 & .52 & .86 & & \\
\hline 5. Training system quality & .88 & .56 & .44 & .38 & .58 & .85 & \\
\hline 6. Intention & .93 & .47 & .65 & .53 & .61 & .50 & .82 \\
\hline \multicolumn{8}{|c|}{$\begin{array}{l}\text { 1. CR: Composite reliability. } \\
\text { 2. Correlations were all significant at the } 0.01 \text { level ( } 2 \text {-tailed). } \\
\text { 3. Diagonal elements represent the Average Variance Extracted, } \\
\text { while off diagonal elements are represented by the correlation } \\
\text { among constructs. For discriminant validity, diagonal elements } \\
\text { should be larger than off-diagonal elements. }\end{array}$} \\
\hline
\end{tabular}




\section{Model Testing Results}

The structural equation modeling (SEM) approach is applied using LISREL 8.80 to examine the overall fit of the model, the explanatory power of research model and the relative strengths of the individual causal path. Several model-fit measures were used to express the model's overall goodness of fit: normed fit index (NFI), non-normed fit index (NNFI), comparative fit index (CFI), goodness of fit index (GFI), and standardized root mean square residual (SRMSR). For models with good fit, GFI, NFI, NNFI and CFI should exceed 0.9, and SRMSR should be less than 0.1. Most indices met these conditions (GFI=0.91; NFI=0.93; $\mathrm{CFI}=0.94 ; \mathrm{NNFI}=0.90 ; \mathrm{SRMSR}=0.062$ ). The overall results suggested that the research model provided a reasonably good fit to the data.

The significance of individual paths was examined and summarized in Figure 2. All of the hypothesized paths exhibited a P-value of $<0.05$. The effects of product offerings and information richness on perceived usefulness were both acceptable with path coefficients of $0.44(\mathrm{p}<0.001)$ and $0.49(\mathrm{p}<0.01)$, respectively. These two variables together accounted for approximately $63 \%$ of the observed variance for perceived usefulness. Perceived usefulness had a strong effect on attitude with a path coefficient of $0.65, \mathrm{p}<0.001$ ), which in turn strongly impacted intention. Training system quality also had a positive and strong effect on intention. Training system quality and attitude jointly explained $45 \%$ of the observed variance for intention. Thus, all hypotheses were supported.

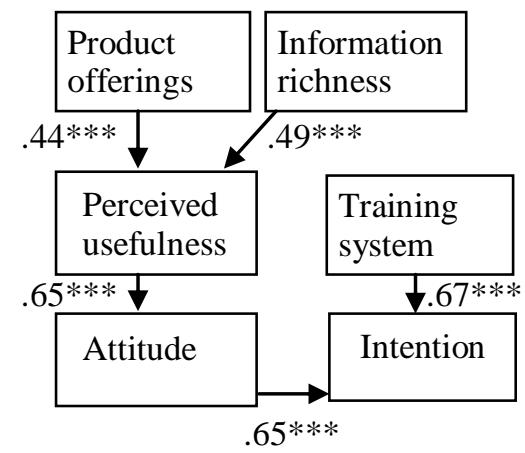

Figure 2. SEM analysis result

\section{Conclusions}

The goal of the present study was to further the understanding of e-tailers' intention to use virtual stores as their selling channel. Several findings are derived from the results. Firstly, consistent with prior TAM-based studies (e.g. Crespo \& Bosque, 2008a; Shih, 2004), attitude is important in predicting e-tailers' intention to use virtual stores. This implies that a stronger favorable feeling of using a virtual store will lead to a higher intention of performing such behavior

Secondly, consistent with prior studies based on IS Success Model, training system quality is able to explain e-tailers' intention to use virtual stores. That means a high-quality training system may help e-tailers to gain knowledge of how to make use of the virtual store to increase their sales volume and revenue. Thirdly, product offerings and information richness respectively and jointly exert a significant influence on 
perceived usefulness, which in turn significantly impacts attitude. This suggests that the variety of products offered in the virtual store and information provided help to lead retailers to gain knowledge of managing business via virtual stores.

\section{Acknowledgements}

This work is supported by the National Science Council, Taiwan under Grants NSC 982410-H-018 -038.

\section{References}

1 Alba, J., Lynch, J., Weitz, B., Janiszewski, C., Lutz, R., Sawyer, A. \& Wood, S. (1997). Interactive Home Shopping: Consumer, Retailer and Manufacturer Incentives to Participate in Electronic Marketplaces. Journal of Marketing, 61(3), 38-53.

2 Amit, R. \& Zott, C. (2001). Value Creation in E-business. Strategic Management Journal, 22(6/7), 493-520.

3 Chen, N.S., Hwang, G.J., Chen, M.P. \& Hwang, W.Y. (2010). Knowledge Management \& E-Learning: An International Journal, 2(1), 1-5.

4 Chen, L.D. \& Tan, J. (2004). Technology Adaptation in E-commerce: Key Determinants of Virtual Stores Acceptance. European Management Journal, 22(1), 74-86.

5 Choo, S. (2007). Using Training and Development to Affect Job Satisfaction Within Franchising. Journal of Small Business and Enterprise Development, 14(2), 339352.

6 Childers, T.L., Carrb, C.L., Peckc, J. \& Carsond, S. (2001). Hedonic and utilitarian motivations for online retail shopping behavior. Journal of Retailing, 77(4), 511535.

7 Crespo, A.H. \& Bosque, I.R. (2008a). Explaining B2C E-commerce Acceptance: An Integrative Model Based on the Framework by Gatignon and Robertson. Interacting with Computers, 20(2), 212-224.

8 Crespo, A.H. \& Bosque, I.R. (2008b). The Effect of Innovativeness on the Adoption of B2C E-commerce: A Model Based on the Theory of Planned Behaviour. Computers in Human Behavior, 24(6), 2830-2847.

9 Daft, R.L. \& Lengel, R.H. (1986). Organizational Information Requirements, Media Richness and Structural Design. Management Science, 32(5), 554-571.

10 DeLone, W.H. \& McLean, E.R. (2004). Measuring E-commerce Success: Applying the DeLone \& McLean Information Systems Success Model. International Journal of Electronic Commerce, Armonk: Fall, 9(1), 31-47.

11 Doherty, A.M. (2007). Support Mechanisms in International Retail Franchise Networks. International Journal of Retail \& Distribution Management, 35(10), 781802.

12 Fornell, C. \& Larcker, D.F. (1981). Evaluating Structural Equation Models with Unobservable Variables and Measurement Error. Journal of Marketing Research, 18(1), 39-50. 
13 Hoffman, D.L., Novak, T.P. \& Chatterjee, P. (1996). Commercial Scenarios for the Web: Opportunities and Challenges. Journal of Computer-Mediated Communication, 1(3).

14 Hsu, C.L. \& Lu, H.P. (2004). Why Do People Play On-line Games? An Extended TAM with Social Influences and Flow Experience. Information \& Management, 41(7), 853-868

15 Igbaria, M., Iivari, J. \& Maragahh, H. (1995). Why Do Individuals Use Computer Technology? A Finnish Case Study. Information \& Management, 29(5), 227-238.

16 Jarvenpaa, S.L. \& Todd, P.A. (1997). Consumer Reactions to Electronic Shopping on the World Wide Web. International Journal of Electronic Commerce, 1(2), 5988 .

17 Kim, H.B., Kim, T. \& Shin, S.W. (2008a). Modeling Roles of Subjective Norms and eTrust in Customers' Acceptance of Airline B2C eCommerce Websites. Tourism Management, doi:10.1016/j.tourman.2008.07.001.

18 Kim, T.G., Lee, J.H. \& Law, R. (2008b). An Empirical Examination of the Acceptance Behaviour of Hotel Front Office Systems: An Extended Technology Acceptance Model. Tourism Management, 29(3), 500-513.

19 Moon, J.W. \& Kim, Y.G. (2001). Extending the TAM for a World-Wide-Web Context. Information and Management, 38(4), 217-230.

20 Price, S. (1993). Performance of Fast-food Franchises in Britain. International Journal of Contemporary Hospitality Management, 5(3), 10-16.

21 Sayler, T. (2003). The Single Most Significant Event in the Life of a Franchise Relationship. Franchising World, 35(4), 13-15.

22 Shang, R.A., Chen, Y.C. \& Shen, L. (2005). Extrinsic Versus Intrinsic Motivations for Consumers to Shop On-line. Information \& Management, 42(3), 401-413.

23 Shih, H.P. (2004). An Empirical Study on Predicting User Acceptance of E-shopping on the Web. Information \& Management, 41(3), 351-368.

24 Thomas, R., Lashley, C. \& Eaglen, A. (2000). The Benefits of Training in Leisure Retailing: a Case Study of McDonald's Restaurants. Strategic Change, 9(6), 333-45.

25 Woodside, A.G. \& Trappey, R.J. (1992). Finding out why consumers shop your store and buy your brand: automatic cognitive processing models of primary choice. Journal of Advertising Research, 32(6), 59-77.

26 Yesil, M. (1997). Creating the Virtual Store: Taking Your Web Site from Browsing to Buying. John Wiley, New York.

27 Yu, J., Ha, I., Choi, M. \& Rho, J. (2005). Extending the TAM for a t-commerce. Information \& Management, 42(7), 965-976.

28 Zhang, D. \& Nunamaker, J.F. (2003). Powering E-learning in the New Millennium: an Overview of E-learning and Enabling Technology. Information Systems Frontiers, 5(2), 207-18. 